\begin{tabular}{|c|c|c|c|c|c|c|}
\hline irAEs & $\mathrm{n}$ & frequency & $\begin{array}{c}\text { Time } \\
\text { (months) }\end{array}$ & Treatment & $\begin{array}{c}\text { Discontinuation of } \\
\text { immunotherapy }\end{array}$ & Response to treatment \\
\hline Gastrointestinal tract & 17 & $13.6 \%$ & 4 & $23 \%$ steroid & $58 \%$ no & $17 \%$ steroid \\
\hline Colitis & 8 & & & $5 \%$ Infliximab & $29.4 \%$ definitive & 83\%improvement \\
\hline Intestinal perforation & 1 & & & $72 \%$ nothing & $11.7 \%$ temporary & \\
\hline Hepatitis & 8 & & & & & \\
\hline Endocrine glands & 11 & $8.8 \%$ & 4 & $18 \%$ steroid & $90 \%$ no & $63 \%$ stable \\
\hline Hypophyisitis & 1 & & & $82 \%$ Other & $10 \%$ definitive & $37 \%$ improvement \\
\hline Hipothyroidism & 7 & & & & & \\
\hline Adrenal insufficiency & 2 & & & & & \\
\hline Other & 1 & & & & & \\
\hline Skin & 10 & $8 \%$ & 4 & $20 \%$ steroid & $60 \%$ no & $100 \%$ improvement \\
\hline Rash/Prurito & 7 & & & $20 \%$ topic & $30 \%$ definitive & \\
\hline Vitíligo & 1 & & & treatment & $10 \%$ temporal & \\
\hline Other & 2 & & & $60 \%$ other & & \\
\hline Rheumatological & 7 & $5.6 \%$ & 5 & $20 \%$ steroid & $72 \%$ no & $100 \%$ improvement \\
\hline Arthralgias & 3 & & & $20 \%$ local & $28 \%$ definitive & \\
\hline Polymyalgia rheumatic & 1 & & & treatment & & \\
\hline Sicca syndrome & 1 & & & $60 \%$ other & & \\
\hline Inflammatory & 1 & & & & & \\
\hline myopathy & 1 & & & & & \\
\hline \multicolumn{7}{|l|}{ Tenosynovitis } \\
\hline Haematological & 4 & $3.2 \%$ & Not available & $25 \%$ steroid & $50 \%$ no & $25 \%$ death \\
\hline Thrombocytopenia & 2 & & & & $25 \%$ definitive & $75 \%$ improvement \\
\hline Neutropenia & 1 & & & & $25 \%$ temporal & \\
\hline Pancytopenia & 1 & & & & & \\
\hline Lung (Pneumonitis) & 3 & $2.4 \%$ & 12 & $100 \%$ steroid & $\begin{array}{l}66 \% \text { defintive } \\
33 \% \text { temporary }\end{array}$ & $\begin{array}{c}33 \% \text { stable: } 33 \% \text { improvement; } 33 \% \\
\text { death }\end{array}$ \\
\hline Ophthalmologic & 1 & $0.8 \%$ & Not available & Not available & Not available & Not available \\
\hline Neuropathy & 1 & $0.8 \%$ & 2 & steroid & Not available & Improvement \\
\hline Cardiac & 1 & $0.8 \%$ & Not available & Not available & Not available & Not available \\
\hline
\end{tabular}

\section{THU0632 IDENTIFICATION OF ABERRANT T-CELL PHENOTYPE IN EPISODIC ANGIOEDEMA WITH HYPEREOSINOPHILIA (GLEICH SYNDROME) IN 30 PATIENTS: FREQUENCY, CLINICLAL IMPLICATION AND PROGNOSIS}

N. Abisror ${ }^{1}$, A. Mekinian ${ }^{1}$, A. Dechartres ${ }^{2}$, O. Fain ${ }^{1}$, J.E. Kahn ${ }^{3}$, on behalf of Guillaume Lefevre, Alice Berezne, Nicolas Noel, Chafika Morati, Julien Haroche, Mathilde Hunault-Berger, Christian Agard, Matthieu Groh, Loïk Geffray, Pierre Yves Jeandel, Sébastien Trouillier, Thomas Quemeneur, Jean François Dufour, Isa. ${ }^{1}$ Internal Medicine, Sorbonne Université, APHP Hopital Saint Antoine; ${ }^{2}$ Center for Clinical Epidemiology, Hôtel Dieu, AP-HP,, Paris; ${ }^{3}$ Service de Médecine Interne, Université Versailles Saint-Quentin-en-Yvelines, Centre de Référence des Syndromes Hyperéosinophiliques (CEREO), Hôpital Foch,, Suresnes, France

Background: Gleich's syndrome or "Episodic Angioedema with eosinophilia"(EAE) is a rare disorder characterised by recurrent episodes of angioedema, concomitant hypereosinophilia and frequent elevated serum Immunoglobin $\mathrm{M}$ (IgM) levels. So far, no series were reported in literature.

Objectives: In this retrospective French study we report the clinical spectrum and therapeutic management of patients with EAE in a large French nationwide retrospective multicenter cohort study, with a particular focus on lymphoid variant of hypereosinophilic syndromes-related EAE.

Results: Thirty patients were included with a median age at diagnosis of 41 years ${ }^{5-84}$ and a median follow up duration of 53 months. ${ }^{31-99}$ The median time between two angioedema crises was 30 days $^{7-192}$ and the median duration of each crisis was 5.5 days ${ }^{1-90}$ with swelling affected the face, the neck, the upper limbs, and the lower limbs. Twelve patients $(40 \%)$ had an abdominal. The median blood eosinophil count at diagnosis was $6.9 \mathrm{G} / \mathrm{L}$ [1.44-53.5] and total serum IgM levels were increased in 20 patients (67\%). Abnormal T-cell immunophenotypes were detected in 12 patients $(40 \%): C D 3-C D 4+$ in 8 patients, CD3 +CD4+CD7 in 2, CD3-CD3ic+CD4 CD8-CD5+CD7 in 1 patient and CD3 +4-8-2+5+7+TCR $\gamma \delta$ in 1 patients with presence of clonal TCR $\gamma$ gene rearrangement in 5 cases (17\%). Fourteen patients $(47 \%)$ had bone marrow cytology and/or histology revealing high eosinophil counts and/or infiltration by non-dystrophic eosinophils in all cases. Eosinophilic perivascular infiltration (without vasculitis) was reported in 2 patients $(7 \%)$ in which a skin biopsy was performed. An eosinophilic infiltrate was also found in various organs (stomach, gallbladder, liver, ileon, and colon) that were biopsied and/or surgically removed.

All 30 patients were initially treated with glucocorticoid with a median initial dose of $40 \mathrm{mg}$ of daily prednisone. ${ }^{5-80}$ After first line treatment and a median time of 15.2 months (95\% Cl: 9.4-50.1), disease was considered as uncontrolled in 24 patients $(80 \%)$ with relapses in 15 patients $(50 \%)$ or glucocorticoid's dependence in $9(30 \%)$.

Glucocorticoid-sparing agents were used in 14 cases $(47 \%)$ for relapses $(n=8)$ or glucocorticoid- dependence $(n=6)$. Associated treatments consisted of interferon$\alpha(n=8,27 \%)$, mepolizumab $(n=2,7 \%)$, ciclosporin $A(n=5,17 \%)$, methotrexate $(n=4,13 \%)$, hydroxycarbamide $(n=2,7 \%)$.
The presence of an abnormal T-cell population was the sole factor associated with a shorter time to relapse (hazard ratio 4.15 [Cl 95\% 1.18-14.66; $p=0.02$ ).

Two deaths occurred during follow-up (7\%) due to lymphoma evolution for one and unexplained sudden death for the other.

Conclusions: EAE could be classified as a lymphoid variant of hypereosinophilic syndrome but that it is an heterogeneous condition. Although patients usually respond well to glucocorticoids, those with a circulating T-cell clonal population are at higher risk of both relapse and lymphoma suggesting necessity to long-term treatment and close monitoring.

Disclosure of Interest: None declared

DOI: 10.1136/annrheumdis-2018-eular.4314

\section{THU0633 ACUTE FROM OF SARCOIDOSIS (LÖFGREN SYNDROME) IN RHEUMATOLOGY PRACTICE}

O.N. Egorova' ${ }^{1}$, B.S. Belov', S.G. Radenska-Lopovok ${ }^{2} .{ }^{1} F S B I$ V. A. Nasonova Research Institute of Rheumatology, ${ }^{2} 1$ FSBEIHE I.M. Sechenov Moscow State Medical University, Moscow, Russian Federation

Background : Löfgren syndrome (LS) is the acute form of sarcoidosis, characterised by erythema nodosum (EN), joints involvement, fever and intrathoracic lymphadenopathy. LS clinical polymorphism leads to diagnostic errors.

Objectives: To study the clinical, laboratory and radiological features of early stages of sarcoidosis in a cohort of patients referred to rheumatology centre.

Methods: The study included 125 patients (104 females and 21 males, mean age $42 \pm 12 \mathrm{y}$ ) with clinical and radiological features of LS. All patients were referred to rheumatology centre with EN diagnosis. The median duration of disease was 1 $(0,5-2,0)$ months. All patients were subjected to comprehensive clinical and laboratory-instrumental examination, including biochemical panel and immunological parameters, chest X-ray or CT, as well as (15 cases) histopathology examination of nodular biopsy specimens of the skin and subcutaneous fat.

Results: In $97 \%$ pts EN involved the lower legs, mostly the anterior surface, in $35 \%$ - the hips, in $25 \%$ - the upper limbs and in $3 \%$ - the trunk. Symmetric lesions were documented in $50 \%$ of patients. Confluence of nodules forming conglomerates was registered in $48 \%$ pts. The involvement of more than $50 \%$ of lower leg surface $(68 \%)$ was directly associated with the number of nodules $(p<0.001$; $r=0.60)$ and $C$-reactive protein level $(p=0.006 ; r=0,38)$. There was a direct correlation between the number of nodules and EN duration $(p=0.04 ; r=0.20)$, and also the tendency to nodules confluence $(p<0.001 ; r=0,39)$. Joint involvement was documented in $106(85 \%)$ patients, with predominantly ankle $(66,4 \%)$ and knee $(40 \%)$ joints affected. Asymmetry of joint involvement was documented in $8 \%$ pts. Articular manifestations preceded the emergence of EN in $35(28 \%)$ patients by mean $12 \pm 9$ days. There was a significant direct correlation between the duration of articular syndrome and appearance of nodules and their number $(p=0.02$; $r=0.45$ ). Joint involvement after EN manifestation - in an average $12 \pm 7$ days was documented in $10 \%$ of cases. Male gender (odds ratio (OR) 6.5 ; confidence 